\title{
Conceptualization of a new generation of smart energy systems and the transition toward them using anticipatory systems
}

\author{
Zahra Heidari Darani ${ }^{1}$, Mohsen Taheri Demne 1* $^{*}$, Darush Mohammadi Zanjirani ${ }^{2}$ and Ali Zackery ${ }^{1}$
}

\begin{abstract}
Emerging energy systems are inherently different from their conventional counter-parts. To address all issues of these systems, comprehensive approaches of transdisciplinary and post-normal sciences are needed. This article tries to re-conceptualize emerging energy systems using Robert Rosen's theory of anticipatory system and introduces the concept of the anticipatory smart energy system (ASES). Three important features of an ASES are described and socio-technical considerations for realization of these features are discussed. The article also considers realization of such systems under society 5.0 paradigm and spime techno-culture. In ASESs, the identity of users evolves and new identities are created for energy users, based on the production, consumption, storage, and distributed management of energy. An Anticipatory energy system can manage a common pool of prosumaging.
\end{abstract}

Keywords: Rosen's anticipatory system, Spime techno-culture, Wranglers, Society 5.0 paradigm, Smart energy systems

\section{Introduction}

In technical and social systems preparation for the future is conducted in various ways from forecasting to simulation, from planning to trend extrapolation, and from scenarios to anticipation [1]; some of these approaches have been used to investigate and harness the uncertainties associated with nascent energy systems [2-4]. Recently, anticipation and anticipatory systems have drawn attention "as a mediating process between knowledge and action" in socio-technical systems [5]. Underlying features of anticipatory systems can be utilized in any socio-technical sphere including energy, sustainable development, and public health [6]. In this article we have tried to apply anticipatory systems to re-conceptualize SESs and investigate transitions toward it.

\footnotetext{
${ }^{*}$ Correspondence: m.taheri@ast.ui.ac.ir

${ }^{1}$ Department of Industrial Engineering and Futures Studies, Faculty

of Engineering, University of Isfahan, Isfahan, Iran

Full list of author information is available at the end of the article
}

Decentralization and the cyber-physical integration have shaped SESs. Amalgamation of energy consumption, production, distribution, global energy supply, and demand, various energy resources such as fossil fuels and their alternative fuels, RE resource, economic and environmental aspects [7] and the social impact of each one on human life and the dependence of governance on it, has transformed energy field to a complex area [8-13]. Essentially, these energy systems - as socio-technical systems - are "more than the sum of [their] elements" [14] and are under the effect of multiple drivers of change [15]. Therefore, energy research should be purposeful, systematic and problem-focused [16]. Disciplinary approaches single-handedly are not sufficient to study and theorize about SESs. Borrowing from Popper (1963), energy field scientists are not students of some subject matter, but students of problems. And problems cut right across the borders of any subject matter or discipline [17]. For this reason, some interdisciplinary [18] and multidisciplinary approaches $[19,20]$ have been proposed. For example, integration of social and technological aspects 
of SESs with help of information and communication sciences has created some interdisciplinary fields, namely, 1. Energy informatics [21-23]; 2. Social informatics [21, 24-28]; 3. Energy Social Sciences [21, 29, 30]; 4. Social energy informatics [21].

While interdisciplinarity and multidisciplinarity offer substantial added value in grappling with problems of SESs, transdisciplinary approaches which consider users as active participants across energy supply chain as opposed to passive consumers are the missing chain; therefore, interdisciplinarity and multidisciplinarity plus actors' participation can solve real-world problems of energy systems [31]. In fact, actors' participation is a key concept of post-normal science [32].

Anticipation as a transdisciplinary approach, is an active future sense-making and a way to include collective action and actors' participation [33]. Studying social anticipatory capacity is not truly feasible without a model-based approach [34]. Rosen (1991), believes: "perception of anticipatory systems is crucial for planningbased decision making" [35].

This paper aims at providing insights on the SESs using an anticipatory system perspective to criticize and enhance top-down and disciplinary existing energy system approaches; it highlights the significance of bottomup, transdisciplinary and post-normal approaches as the possible future complement/alternative of conventional approaches.

In this paper, we review the transdisciplinary problems of emerging energy systems with transdisciplinary solutions presented in the literature, then we introduce the concept of anticipatory systems and its three features. Subsequently, we describe its relevance and significance in management of SESs. In fact, we provide reconfiguration of SESs and their problems and solutions from the perspective of anticipatory system as a transdisciplinary lens. Juxtaposition of familiar and frequently-used concepts of SESs with those associated with anticipatory systems sheds light upon incipient energy systems.

\section{The problems of energy systems in transition era}

In the literature, a wide array of technical problems concerning the emerging energy systems have been reviewed and solutions have been presented [36-52]. At the heart of this approach, there is a top-down, disciplinary and merely technical essence trying to reduce problems and solutions to physical aspects and to SGs. Nonetheless, there is ample evidence that emerging energy systems are social grids and need to be embraced by post-normal, social, transdisciplinary and bottom-up approaches. The following table is a collection of problems and proposed solutions concerning the social grid and is the result of a systematic literature review. In the identification phase of the systematic review, a comprehensive analysis of the review papers related to SESs published in top 10 interdisciplinary journals of energy was conducted to provide an initial array of keywords. This array was then combined with our list to do the systematic review. Our key words included but were not limited to: smart energy systems, future of energy systems, interdisciplinary energy systems, trends of energy systems, emerging technologies of energy systems, social aspects of energy, barriers of smart energy systems and integrated energy systems. The database sources used were Scopus, Google Scholar, and IEEE. The period studied ranges from 2010 to 2020 and the search was carried out using the "Title/Abstract/Keyword" field of the databases. 284 papers were chosen. In the screening phase, non-English and conference papers as well as duplicates were removed giving us total of 153 articles. In the next step, the papers were scanned by two of the authors independently and two separate lists were created. The lists were compared and finally 31 papers were selected for full analysis. As for our exclusion/inclusion criteria, a substantial chunk of the literature focused on merely technical/hard aspects and problems of SESs (Fig. 1). Our focus, though, was on the inter/trandisciplinary side of theses system. In other words, based on our approach which is inherently inter/transdisciplinary, we focused on human/participatory/soft aspects of SESs. Therefore, Table 1 gives quite a comprehensive list of inter/transdisciplinary issues of SESs which have a social, economic, cultural or environmental dimension.

After introducing the concept of anticipatory systems, we will try to create a broader picture of some these problems and solution in the light of anticipatory systems.

\section{Anticipatory systems: its definition and positioning in future research community}

Anticipation is the ability to look forward to taking a future decision and action, or the visualization of a future event or state [34]. Forming the future of each system is associated with its anticipatory capacity [6]. The anticipatory capacity of the system is the capacity to continuously develop and apply the knowledge acquired to choose the best way for stakeholder needs [34].

Anticipation is the human "sense of context" that enables a system (biological, social, political) to adapt to change [82]. By accurately identifying our situation, we can "create different models of the future" and integrate change. Otherwise, change leads to shock, unpropitious reactions and system failure [83]. New generation of energy systems as a "common pool of prosumption" will face shocks of this nature such as frequent shut downs of the utility grid because of uncertainty in availability of RE sources as well as distributed and decentralized 


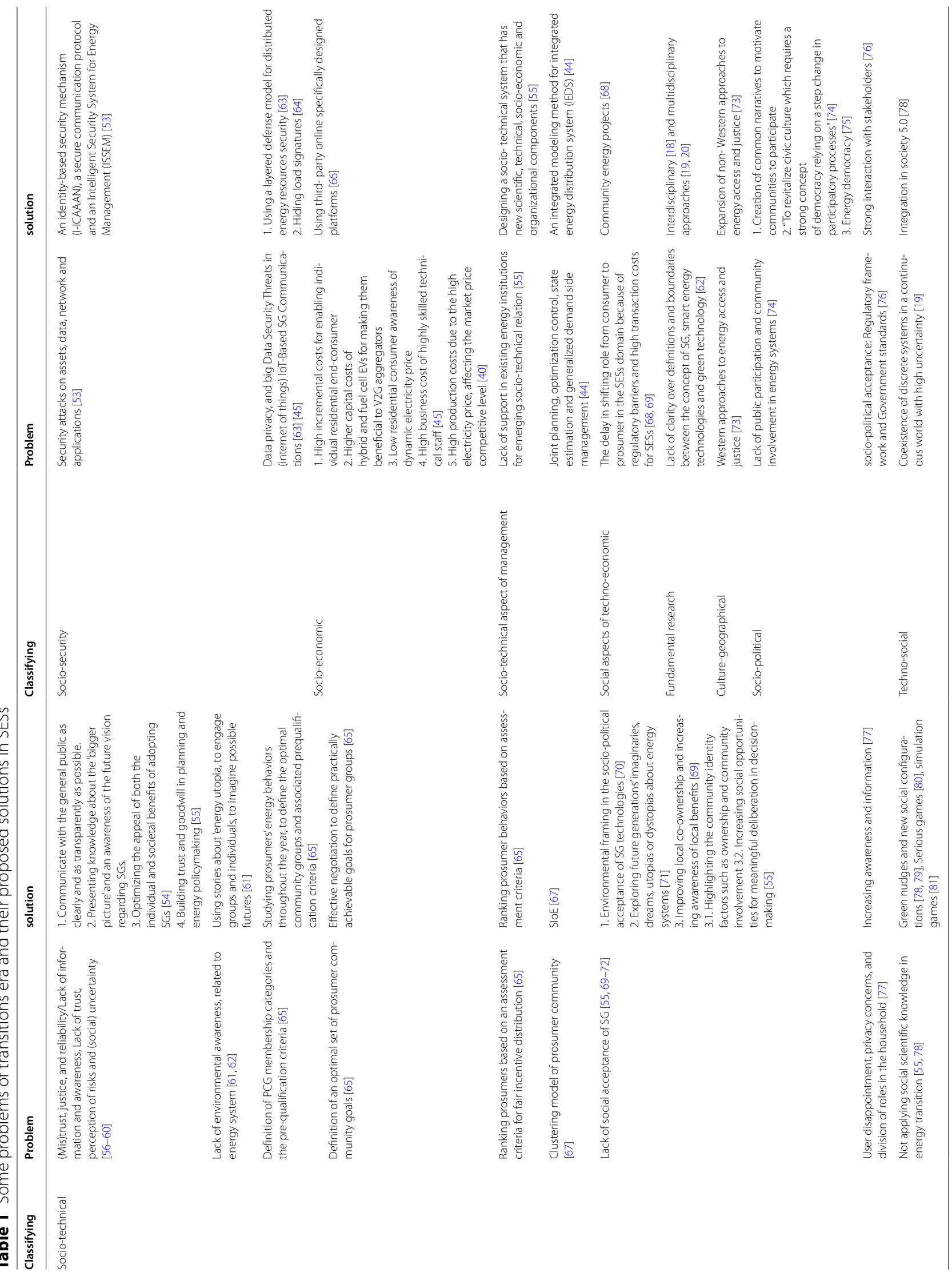


- Using review papers of SESs to constrcut an initial set of keywords

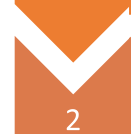

-Database searching in Scopus, Google Scholar and IEEE ( $n=284)$, Period: (2010-2020)

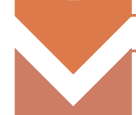

3

-Non-English and conference papers as well as duplicates removed $(n=153)$

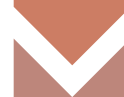

4

- Abtract analysis of papers by two authors independantly

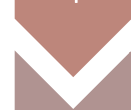

- Comparig two selections and finalizing the list based on inclusion/exclusion criteria

5 $(\mathrm{n}=\mathbf{3 1})$

Fig. 1 The process of conceptual literature review

production. The speed and volatility of change in this system increases its complexity [83].

The theory of anticipatory systems was developed by Robert Rosen. He claims that the development of anticipatory systems theory would lay the foundations for what may be called an anticipatory paradigm [84] in contrast to reactive paradigm. So what is an anticipatory system? Robert Rosen (2012) defines the anticipatory system as follows:

"An anticipatory system is a system containing a predictive model of itself and/or its environment, which allows it to change state at an instant in accord with the model's predictions pertaining to a later instant" [84].

Anticipatory systems can be an important step in responding to the challenge of unpredictability and its consequences [85-87]. Rosen (1974), notes that from anticipatory architecture, "different views on the nature of "planning", "management", and "policies" can be extracted" [88], and a "technology of policy generation" can be devised [89]. This new window to planning for the future of system refers to difference between prediction and anticipation. Anticipation considers a variety of future possibilities and thus the current state of an anticipatory system depends not only on a previous state, but also upon possible future states [82, 83]. It adjusts present behavior in order to address future problems [1], whilst, prediction talks about probabilities in future. Anticipatory systems involve predictive models and their environment, and these models are used to control current activities [82, 84]. Control is essential in conceptualizing the difference between reactive and anticipatory systems: reactive control (feedback controllers) corrects existing deviation, while anticipatory control (feed-forward controllers) depends on predicted deviation that monitors the system $[1,89,90]$. Therefore, an anticipatory system is a self-observing and self-referential system [1].

The concept of anticipatory systems "has received attention as a part of a growing discourse on Anticipation" [5] and have been used as a theoretical perspective by the futures research community. The special issue of foresight journal [91] contends that Rosen's anticipatory systems can help to improve the philosophical foundations of foresight. Roberto Poli (2010), traces the concept of anticipation in variety of disciplines and distinguishes between anticipation as an empirical phenomenon, on the one hand, and investigation of internal structure of anticipatory systems, on the other hand [1]. In another paper, Poli (2010) reviews some subtleties and complexities of Rosen's work and states that anticipation as a capacity does not exclusively belong to humans as cognitive agents but is present in all types of realities [85]. As a student of Rosen, Louie (2010) states the predictive component of an anticipatory system can make future a constitutive component of the present and shift the focus from "what future is" to "how it should be used" [89]. 
Rossel's paper (2010) directly addresses the question of how we can use anticipatory systems in tackling complex social dynamics. He propounds that the original mathematic-oriented theory of Rosen cannot be used for this purpose unless it is "reinforced by other theoretical considerations." His suggestion is to use framing and metaframing for reinforcement of the concept of anticipatory systems [92]. Fuller (2016), discusses scenario planning in the light of Rosenian anticipatory systems and suggests that epistemology of anticipatory systems combined with methodology of post-normal sciences can "be used to reduce Cartesian anxiety with respect to ontological insecurities of uncertain times" [5]. Cevolini (2016) boldly claims that "Social sciences are experiencing an anticipatory turn. He refers to self-referential dynamics - as Robert Rosen does - of an anticipatory detector between weak and strong signals [93]. In a similar vein, Poli (2014) speaks of turning human and social science upside down with the advent of anticipation [94]. Chiffi et al. (2020) argue that anticipation in science is valuedependent and values can be interpreted in epistemic and moral senses or from a social, political, and strategic aspects [95]. Kazakov and Kunc (2016) apply the concept of anticipatory systems to re-conceptualize the dynamics of strategy. They propose that "modeling and simulation can improve managers' mental processes and help them to overcome cognitive limitations" [96]. Distinctions have also been made between implicit and explicit anticipation as well as strong and weak anticipations. Poli (2010) defined explicit anticipation as predictions and expectations which system is aware of. In contrast, implicit anticipation is a type of anticipation that the system is not aware of and is active within the system [1]. Dubios (2003) differentiates strong anticipation form weak one. Strong anticipation is built by system itself or embedded within it whereas weak anticipation is based on the model of external environment of the system and can be compared with predictions and expectations [97]. But, what are the constituent element of an anticipatory system?

The model of Rosen's anticipatory systems begins with the $\mathrm{S}$ system, which may be an individual organism, an ecosystem, a social or economic system. The second system $-\mathrm{M}-$ is a model of $\mathrm{S}$. The only prerequisite is that the dynamic evolution of $\mathrm{M}$ is faster than the dynamic evolution of S [88], and acts in real-time so that the overall system can predict changes to the environment [5]. A set of $E$ effectors (E) allows $M$ to operate on $S$ or on environmental inputs to $\mathrm{S}$ to alter the dynamics of $\mathrm{S}$. As Rosen mentioned, "M sees the future of $S$ because $M$ trajectories are faster than $S$ trajectories" [98]. Figure 2, illustrates the logical links between $S, M$ and $E$ in a very simple way.
According to Rosen's theory, the main features of this architecture are as follows:

1. $\mathrm{M}$ and $\mathrm{S}$ are coupled;

2. $M$ is not unique;

3. The resultant signal from $M$ triggers action in system $S$.

Rosen introduces the concept of anticipatory systems with a mathematical/hard system approach that deals with weak and explicit anticipatory model. If we want to use such a strong and implicit model to study future energy systems, it must be a combination of social and engineering systems. As Marien (2009), highlights "technopia" and technical solutions cannot single-handedly lead to anticipatory systems [100]. Rossel (2010) suggests using constructivist approaches and considers $\mathrm{M}$ as framing and meta-framing [92]; therefore, $M$ cannot include only technical issues and must be developed as a socio-technical system. Caillol (2016), puts emphasis on decentralization and network-based organization. For him, $M$ is essentially information. Fuller (2106), explains about uncertain environments in social systems, and the necessity to recognize multiplicity of modeling relations [5]. In his idea, $\mathrm{M}$ can be regarded as scenarios. In our paper, we have followed Rossel's suggestion to combine the perspective of anticipatory systems with other theoretical considerations to re-conceptualize the complex SESs.

\section{How can we create an ASES}

So how can we develop M? In the case of energy systems, our question is: how can we create an anticipatory energy system? What we are trying to do is applying Rosen's architecture to re-conceptualize socio-technical systems of energy. In this section, we are going to describe three above-mentioned features of the anticipatory system for SESs. Firstly, the nature of coupling of $M$ and $S$ and its significance will be discussed; The second questions is why $\mathrm{M}$ is not unique; and thirdly, we will discuss the most important output of an anticipatory system i.e. actions and how they can be mediated via effectors.

\section{$M$ and $S$ are coupled}

What makes an anticipatory system a practical reality is $M$ (as the model of $S$ ) and $S$ (the physical system under study) being thoroughly coupled. For SES, the anticipatory pre-requisite condition of that coupling is total integration of social and technical (socio-technical), social and physical i.e. closer social distance [55], real and virtual [101], technic and culture of prosumers (techno-culture) [102], production and consumption i.e. prosumption [103], physical and digital (phyigitalization) [104], time and space i.e. spime [102], present and future 


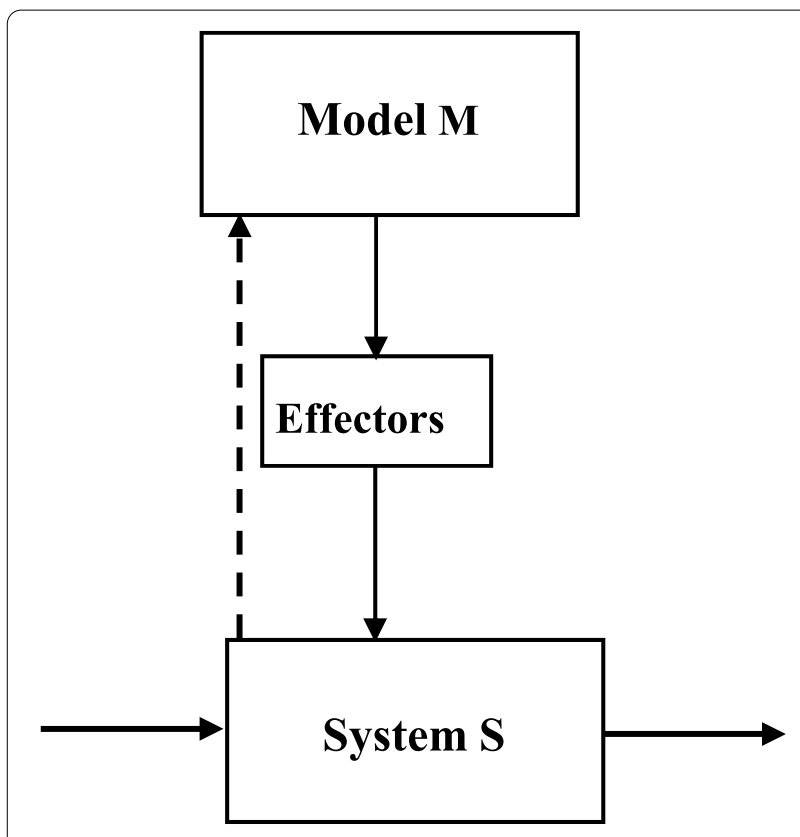

Fig. 2 The internal structure of the simplest anticipatory system [99]

(enlarged present) [83], social and ecological (socio-ecological) [105], electricity prosumption and storage (prosumage) [106], control and prosumption (user-control) [55], prosumers and devices (Social Internet of Energy: SIoE) [107], energy user behavior and actions [108], information technology and power grid, and finally DG units in a cooperative MG [55].

As Mankoff (2013) says, the integration of humans and machine can solve sustainable development problems [109], caused by the rapid and radical changes in technological developments, especially in the energy industry, integrated energy systems have been created to cope with these changes [110]. Particularly, the SES concept, as an integrated energy system, represents a paradigm shift from single-sector thinking to a coherent energy systems understanding, i.e. from centralization to decentralization, and reflects the benefit of the integration of all energy sectors and infrastructures [111]. In fact, SESs offer benefits such as efficiency, effectiveness, cost, integrability, environment protection and reduction of greenhouse gases, resource use, sustainability, and commercial viability [112]. Lack of integration in the traditional analysis of energy systems has culminated in uncertainty [105]. Integration which is manifested in complete coupling of $\mathrm{M}$ and $\mathrm{S}$ is a necessary condition to make an ASES a viable option. Now, how can complete coupling and integration of $S$ and $M$ be achieved so that the whole system will benefit from anticipation as a disposition? The answer is via some key concepts creating integration in SESs, including but not limited to decentralization, VPP, MG, SG, SM, EI or IoE, and EBD, prosumption, spime, wranglers and society 5.0 which will subsequently be reviewed.

We suggest that spime and wrangler as the most important concepts to adequately describe socio-technical aspect of SESs and tackle a wide array of problems discussed in Table 1; We consider spime as an umbrella term for technical integration and wranglers for sociotechnical integration. Also, wrangler and spime are constituent elements of society 5.0.

\section{Spime}

Spime, the integration of space and time, are artificial tools whose information support is vast and rich and can be referred to as the material representation of immaterial systems. They begin and end with data, they are designed on screens, made by digital tools, and tracked precisely through space and time [102]. Spime concept is intended to theorize the ongoing emergence of the very systems and infrastructures, used to trace it and is a theoretical image of future production, consumption and cultural practices [113]. The concept of spime leads to an IoT in its limited state, by transforming the physical world (S) into data (M), enabling foreboding and even future creation, but spime is inherently more "cyclical, ongoing and sustainable" than IoT products $[114,115]$. It is as multidimensional and broader lens [114]. The closer distance of space and time leads the system to act in realtime. For example, being flexible in terms of energy usage means having the ability to shift energy usage in time and space. In this regard, flexibility capital is defined as the capacity to responsively change patterns of interaction with a system to support the operation of that system [116], or control physical processes at multiple time and space scales with pervasive and mobile networks at several sensors and actuator levels [19]. These are anticipatory capacities that let the system act in real-time.

Spime is considered as a tool to represent technical integration of the systems; it includes VPP, MG, SG, SM, EI, EBD and other modern technical concepts in socio-technical SESs. Nonetheless, spime is the emerging techno-culture and has social aspects as well.

From a socio-technical perspective, energy spimes are informationally-rich energy-based data and comprise two-way flow of energy and information produced by users in a wide variety of socially-driven activities in ASESs. Such activities encourage action-learning and social innovations. In order to review ESTs, let us begin with decentralization. Proliferation of RE resources precipitated a paradigm shift from centralized energy resources to decentralized ones [74]. Distributed production and consumption, created DG [55] and distributed 
energy system as an efficient, reliable and environmentally friendly alternative to the traditional energy system [117]. Decentralization is in essence a socio-technical integration which not only transformers the role of end users but alters the essential hierarchical architecture and top-down management of existing energy systems.

\section{Energy spime tools}

ESTs, as symbol of technical integration in our view, are a new category of space-time, location-aware, environment-aware, self-logging, self-documenting, uniquely identified energy devices that provide a lot of data about themselves and their environment [118] and are selfhealing [21].

For example, VPP as an EST, is a cloud-based distributed power plant [119] and refers to the integration of diverse sources of DER which enables management of large-scale power grid flexible capacity [120]. VPPs are often ad-hoc prosumer groups that are connected through an electricity grid [65]. A community-based VPPs is as a novel model for energy provision [121].

Another EST is MG, a socio-technical small-scale power grid designed for a low voltage distributed system [122]. Technically, MGs increase resilience during major disturbances [123]. The actors who 'decide' to integrate their DG units in a cooperative MG constitute a community [55]. MGs can be considered as CPRs in Ostrom's theory [124]. Integrated MGs build SG, a larger grid and socio-technical network of both information and energy flows, in order to control practices of production, consumption, storage and flexible demand [55], storing, communication system, and decision making in real-time [125-127]. In fact, SG is an electricity network that can intelligently integrate all the behavior and actions of all users connected to it [108]. The next generation of SG is the 5th generation SG based on Light Fidelity or Li-Fi technology that uses radiofrequency [128] and is creating a boom in the new EI. The function of 5G SG as an energy spime tool will make $\mathrm{M}$ and $\mathrm{S}$ more coupled resulting in a higher degree of integration in all previously discussed aspects of ASESs.

The next EST is SMs which are networks of energy flows and information which monitor, display and control energy demand and supply from various sources, account storage capacity and consider the patterns of loads of all equipment [55].

EBD is also an EST that unfolds historical precedents and future opportunities of user energy life style. EBD can optimize electricity generation, distribution, and operations in real-time for better planning [129] by accurately forecasting electricity demand and detecting electricity consumption patterns, detecting and repairing failures effectively, developing a dynamic pricing mechanism and enabling customers to have more control over their energy use [124]. Therefore, analyzing an EBD can be used to anticipate SESs future changes [125].

EI is a new energy spime, integrating RE, distributed power plants, storage technologies and EVs [130], modern electronic technology, new energy technology, and information technology to coordination [131]. The EI features are a combination of SG and IoT features [132, 133]. A future perspective for EI, on one hand, is its combination with block chain technology, which can act as an effective technical way to share information and update model in a decentralized operational framework with a cloud-based energy management system platform [134]. On the other hand, SIoE will integrate prosumers and devices via social relationships [56]. Community and SIoT, the combination of block chain technology with EI and SIoE are manifestations of future higher levels of integration. Figure 3 summarizes ESTs. In an ASES, some of these ESTs are absolutely essential in designing the technical signals for effectors.

\section{Wranglers}

Sterling (2005), points to the evolution of the human role in various techno-cultures in a chronological order: the techno-culture of artifacts, machines, products, gizmos, and spime. He calls human identity and role in each of these techno-cultures, respectively the "farmer and the hunter", "the customer", "the consumer", "the end-user", and "the wrangler", and emphasizes that the evolution of these techno-cultures is linear and irreversible [102]. Wranglers are the people who interact with spime [102]; and experience the maximum integration between cyber and the physical as well as real and virtual spaces.

\section{New energy identities: from consumer to prosumager}

Along with Sterling's point of view as a futurist, Ritzer (2009), dubbed coming century as the "age of the prosumers" [135]. Prosumer identity is created by integration of producer and consumer as Toffler explains [103]. ubiquity of the internet, it has gained popularity and significance in many areas [136-139]. Of course in SESs, the prosumer identity transforms identity of passive users of energy and personalizes the process of energy use [21, 140]. So, prosumers produce and consume RE, store surplus energy for future use, or trade energy with other energy customers on their respective SG [141]. They are next generation of prosumers and are called prosumag$\operatorname{ers}^{1}[106,142,143]$. who store their energy surplus in a distributed storage network [106].Therefore, a new identity is defined for prosumer in the future of energy

\footnotetext{
${ }^{1}$ A coinage for an energy prosumer who produces, consumes and stores.
} 


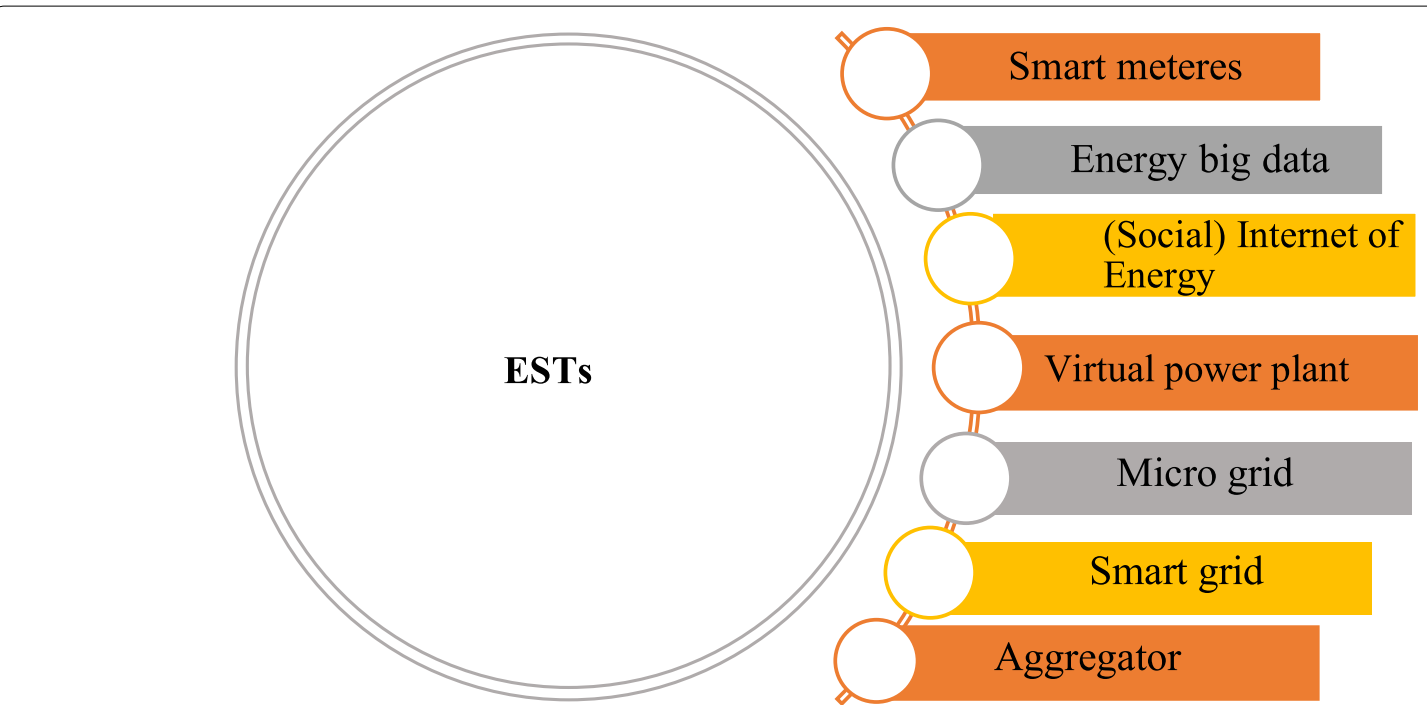

Fig. 3 Energy spime tools

systems which could potentially change energy management in SGs and shift it toward distributed management [144]. New relationships emerge: prosumager-prosumager, prosumager-utility, prosumager -grid manager, prosumager-partners in the MG, which all can be considered as different levels and layers of integration and coupling between $\mathrm{M}$ and $\mathrm{S}$.

As far as the social macro-level is concerned, individual prosumer is too small to compete with traditional energy generators, and individual power supply is unpredictable due to weather conditions. These challenges in productivity and reliability have led to the emergence of PCGs, ICESs, and CECs [65], which hedge risks associated with decentralized energy systems through pooling people.

The PCG refers to "a network of prosumers who have relatively similar energy sharing behaviors" who strive to pursue a common. A group of prosumers that collectively sell energy to the grid and are more efficient and reliable in supplying a sustainable energy source than a prosumer operating as an individual entity or identity [144]. To address the shortcomings in existing prosumer groups", the concept of Virtual Goal-oriented PCG has emerged which is created by virtual integration of prosumers from different locations, but with similar energy behaviors [65].

Also, ICESs have been created to cope with the rapid and radical changes in the energy industry caused by technological developments [110] and are a type of redesign of local energy systems, through DER and the participation of local communities [110, 145].

CECs are another form of prosumer group with purpose of cleaner energy production, consumption, supply, and distribution, that can be centralized, decentralized and dispersed and take many forms, including peer to peer, VPPs, and micro-networks [146].

These communities can create a dynamic ecosystem of prosumer engagement [147], and transform passive consumers into active prosumers, and enhance public engagement in ASESs, because of their micro-network form and internet connection and therefore increases anticipatory capacity of the ASESs.

In sum, looking at the evolution of the role and identity of people in the field of energy, it can be said that prosumager is considered a form of micromanagement that affects the macro-management of energy ASESs.

\section{Society 5.0: integration of integrated society}

Complete coupling of $M$ and $S$ and a very high level of integration between different elements of system will create a socio-technical architecture which is inherently different from its predecessors. The concept of society 5.0 developed by the Japanese government in 2016 can give us an image of what an ASES populated by wranglers might look like. Society 5.0 , based on society 4.0 (information society), is a super-smart and human-centered society [148]. Society 5.0 is a system using digital transformations, network, IoT, EI, Artificial Intelligence, and Robotics which connects 'People to Objects' and the 'Real to Cyber' world [149]; Society 5.0 achieves a high degree of integration between virtual space and physical space. Unlike society 4.0 where big data in cyberspace is analyzed by a human, in society 5.0 , it is analyzed by artificial intelligence [150]. These features will bring new social impacts [149] and enhance the quality of human life [151]. 


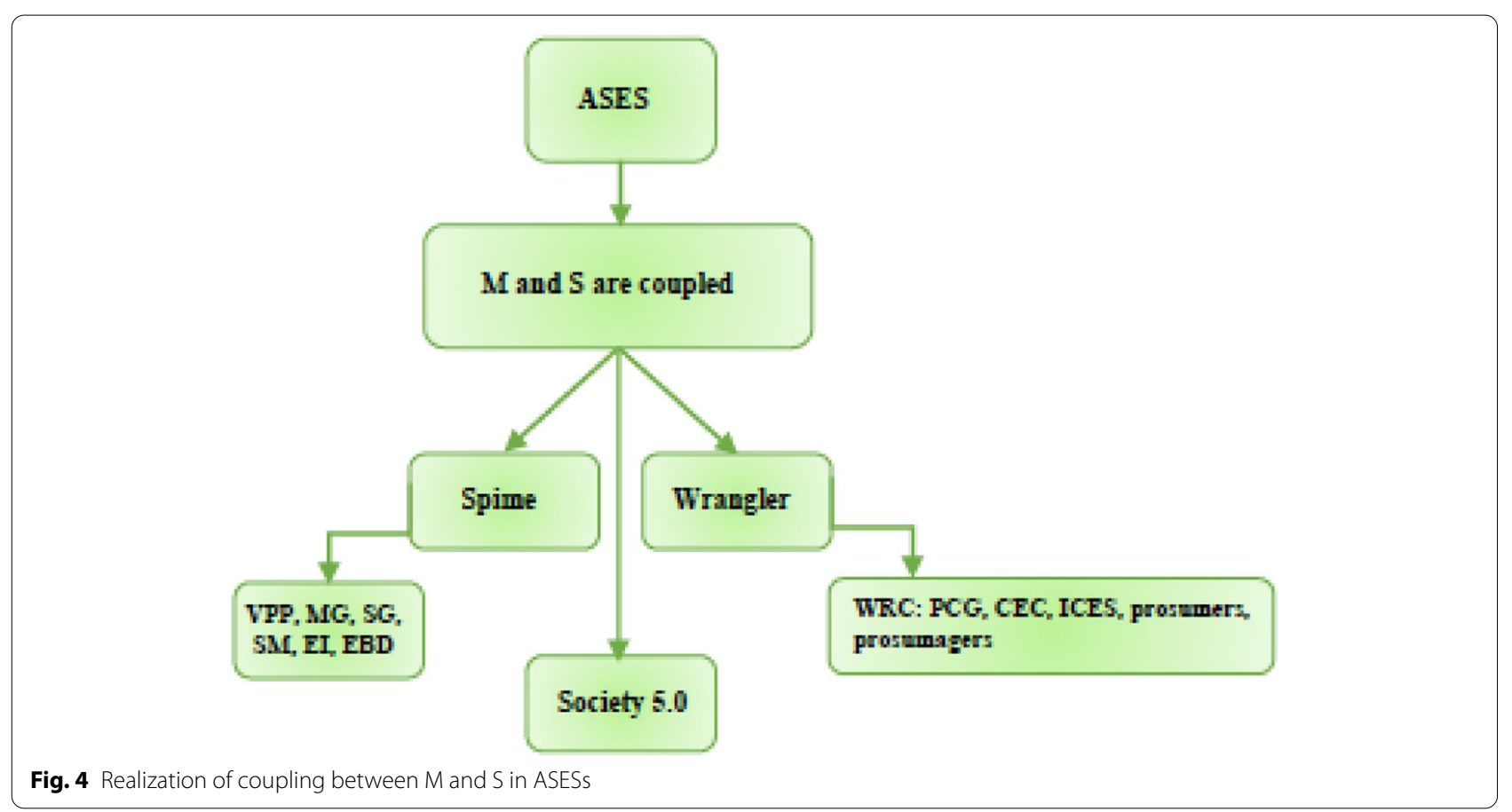

Society 5.0 as a CPSS [152] is born as a result of the paradigm shift from the Newtonian systems to the paradigm of the self-enforcing and self-fulfilling systems. Figure 4 gives a summary how coupling between $M$ and $S$ are achieved in ASESs:

Structural coupling of $\mathrm{M}$ and $\mathrm{S}$ along with sociotechnical integration of machine, information, and society (humans) as well as bidirectional flow of energy and information creates anticipation as a disposition in energy systems i.e. ASESs.

\section{$M$ is not unique}

Technical solutions for energy system problems are insufficient. As far as dealing with ever-increasing environmental complexity is concerned, if $\mathrm{M}$ is considered to be a data-driven centralized commandant control system, it cannot grapple with unpredictable demands of nascent energy systems. As Ashby (1956) proposed, the only thing that can absorb variety is variety [153]. In his view, if the number of system responses is comparable to the complexity of the environment, such a system can counteract the complexity of its environment. Therefore, as dynamics of $\mathrm{S}$ change constantly, $\mathrm{M}$ cannot be singular and unique.

$\mathrm{M}$ is a predictive model, which interacts with 'reality' and intertwines, evolves and adapts in a continuous process of simulation [154]. Prediction in modeling and simulation is to achieve future estimations. On the one hand, prediction can be based on statistics, differential equations, neural networks, cross-impact analysis, and other methods used in hard sciences, and on the other hand, prediction can be done with the help of 'crowdsourcing' and integration of biological and non-biological computations. Simulation, based on crowdsourcing, can be represented by society [155].

In spime techno-culture, new forms of social connectivity and communication unfold and each wrangler functions as a node in a hyper-network over the EI [104] who are both the totality of the network and one of its elements. So perceptions of the wranglers and their responsiveness accelerate [104] leading to the creation of simulated WRCs.

Simulation based on this network of wranglers together with computational capacity of the computers is a kind of crowdsourcing simulation including all prosumagers. Therefore, the network of people in the crowdsourcing process acts like a computer- "network is the computer". In this case, a wide variety of Ms. are created by combining people's expectations in WRCs resulting in an emergent collective intelligence of a community of users who interact in a decentralized manner.

Wranglers as stakeholders of future energy systems, increasingly, have the option to become more self-sufficient by becoming co-prosumagers of electricity and of course controllers of that the system. So production, consumption, storage and control will be distributed and wrangler-oriented. 


\section{The resultant signal from $M$ triggers action in the system} The challenges of any kind of man-made system are enhancing the connection to reality and improving the capacity to translate information into action [83]. Realtime actions in energy systems cannot be achieved by focusing on technical aspects and neglecting the social aspects. Technology and equipment are necessary but insufficient conditions for reliable system operation, human involvement is at least as equally important as technological solutions [77]. So, successful transition toward a fossil fuel-free future through SESs is pre-dominantly a socio-technical process. Nonetheless, lack of attention to the social and behavioral aspects of energy systems results in problems and barriers in developing them $[74,78,156]$.

Socio-technical answers to these problems in Table 1, can play the role of effectors (E) in Fig. 2 for an ASES leading the system to act in real-time. These solutions revolve around human and social aspect of SESs, and are realized through bottom-up public participation. Hybrid computation with the integration of human and machine, helps decision-makers (top-down) or even the public (bottom-up) to participate in the process of shaping and modeling of $\mathrm{M}$ to make its dynamics faster than $\mathrm{S}$. Active involvement of decision-makers and the general public means better coupling between $\mathrm{M}$ and $\mathrm{S}$.

According to problems in Table 1, effectors must enhance social acceptance of SESs, build trust, attract public participation, make sense of justice, reduce risk and social uncertainties, and increase environmental awareness. In fact, effectors (E) should be intended to proactively change the wranglers' behaviors via their participation to enhance anticipatory capacity of the system.

As we mentioned earlier, $M$ and $S$ are distributed decentralized systems, so the effectors (E) will be distributed decentralized systems, too. Some of the effectors are technical and some socio-technical. As for technical effectors, a combination of factors such as ESTs, complete integration between $\mathrm{M}$ and $\mathrm{S}$, maximal translation of physical elements of the system (S) into data (M) datafication - wrangler energy communities and network acting as computer creates feed-forward signals which can be used as effectors to control ASESs. We will focus on some socio-technical effectors which are important in the process of transition toward ASESs. Once an ASES is formed, some of these effectors can be considered as the social component of system's anticipatory capacity. To find socio-technical effectors in the literature, we seek solutions that emphasize wranglers' collaboration in all sections of the energy system, such as co-creation, co-production, communing, and bottom-up energy-(self) production.

To achieve social acceptance, the first kind of effectors are clear and transparent communication with the general public, imaging 'bigger picture' of SESs application, presenting knowledge and awareness of the 'future and long term vision' regarding SGs and optimizing public appeal through both the individual and societal benefits of adopting SGs [54] leading to future-oriented actions. Also, in order to build trust and goodwill, collaborative processes in planning and energy policymaking consistent with theories on building 'social capital' and increasing social opportunities for meaningful deliberation in decision-making [55] have been proposed.

Another kind of effectors highlight democratic processes and public participation such as revitalizing "civic culture" through democracy relying on a step-change in participatory processes in the "energy community". Energy community comes to existence through network communities of wrangler's gathering around energy projects [74]. Another way to generate reliable effectors is via energy democracy which is an emergent social movement, democratically restructuring energy regimes $[75$, 157] and shaping "civic engagement" for a democratic transition to the SES [158]. It is defined as ensuring access to energy, production and consumption of it for all [159]. These kinds of voluntary social movements are distributed and decentralized participation of Wranglers empowering process for "civic engagement" and civic initiative thereby ensuring the anticipatory capacity of the energy system.

Next effector can be exploring 'socio-technical imaginaries' $[12,160-167]$ and dreams, utopias or dystopias" about SESs [71]; That means exploring hidden social dimensions of energy systems and cultural resources of shaping social responses [168, 169] which explain past developments and illuminate prospects for future global cooperation [169]. Exploring the notion of "fantasy" as well as psychological and cultural needs within energy futures, through the development of optimistic, pervasive, but sometimes irrational visions of technological progress and its prospects [162] are other SES effectors. Figure 5 summarizes ASES effectors.

These effectors as "collective social facts" [160] in the distributed wrangler communities increase distributed anticipatory capacity since they trigger and form common conceptions of the desired future. Socio-technical imaginaries are transformation in the "knowing and doing" [167] in future energy systems and are made real by the actions made to achieve collective visions, especially when considering the emergence of multiple visions of the desirable future [170]. Socio-technical imaginaries "connect creativity and innovation" to attain desirable futures which are "collectively held, institutionally stabilized, and publicly performed" [171].

The other set of effectors can be "social innovations" in the energy realm, with high potential to meet 


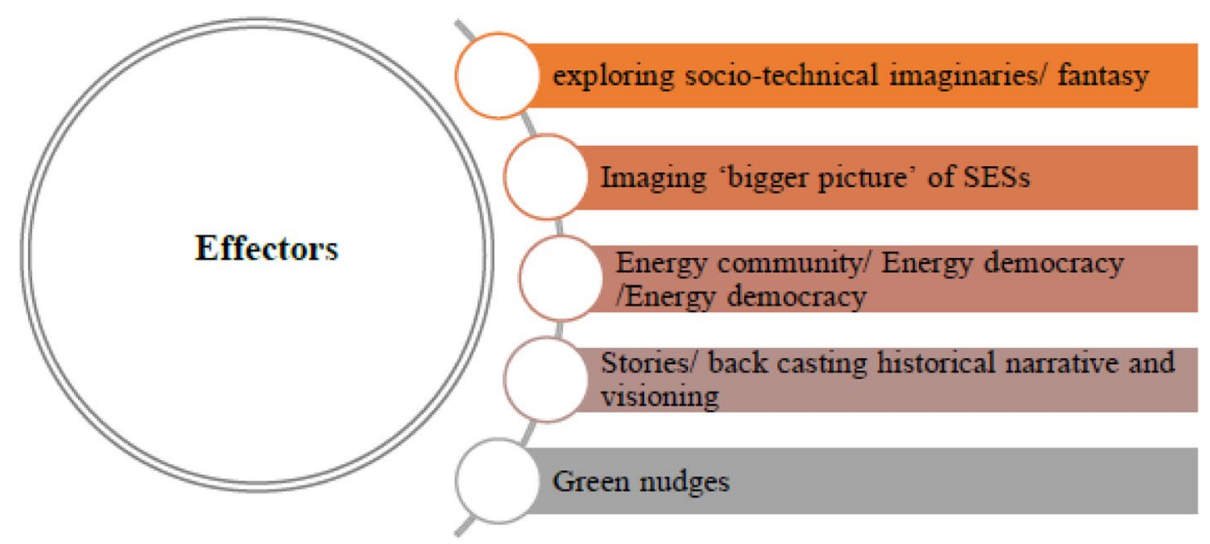

Fig. 5 Some socio-technical effectors of ASES

complexity [78]. Social innovation is any novel and useful solution to a social need or problem which enhances society's capacity to act [172]. For example, "Community energy" projects are described as social innovation. This social movement $[68,78]$ is "creative reconfiguration of social relations" around energy-innovation in forms of actor relationships [173] which raises awareness of sustainable energy issues, improves public receptivity to $R E$ installations, increases engagement in behavior change initiatives and shifts role from consumer to prosumer in SESs $[68,78]$. Community energy projects emphasize wrangler's participation in the common issue of energy [173].

'Green nudges' are another kind of social innovations, aimed at encouraging people to voluntarily contribute to a common source; they are 'new social configurations' to build social networks supportive of RE. They subtly change wrangler's behavior and decision context and gently move them toward sustainable choices without changing monetary incentives [78, 79]. The nudge can also be embedded in simulation, since simulation becomes an integral part of processes of social change [154] as a platform to experience possible futures of socio-technical systems. As an illustrative example, "Gamification" or "serious games" raise awareness and change behavior in SESs [80] and "simulation games" help public understand the socio-technical complexity of energy transition [81].

Also, using stories about 'energy utopia' to engage groups and individuals to imagine possible futures, especially for marginal people of society [61] is another kind of effector. Back-casting [161], back casting historical narrative and visioning [174] are co-creation of narratives which motivate communities [74] about public desired future of SESs; motivate society to make the transition toward sustainable energy systems.

To summarize, based on the extensive literature of this area, we classify two types of effectors for the ASES. The first type is common and collective images of the future of energy systems, technology-backed social imaginations, stories and back casting historical narrative. The second type of effectors are social innovation in the form of social movements such as energy community, community energy, energy democracy that pursue new social networks. Green nudges are between these two categories and can act as a medium and trigger of change. Both types of effects emphasize the engagement and interaction of wranglers, but the latter are more proactive in nature. The second type actually shapes a new configuration of social relations and interaction between wranglers. Both types try to create a big picture of SESs and, all these attempts to understand, imagine, and benefit from the future can be seen as modes of anticipation, a constant feature of human behavior [175].

\section{Anticipatory smart energy systems}

According to Ostrom's definition, renewable natural resources and MGs in SESs as man-made system are CPR [124],. Now, we have a question like Wolsink's, but with difference response: "How would such a common good be managed properly? [55].

Our proposal for the management of this CPR is using ASESs based on spime tools, principles of society 5.0 and high levels of integration between real and virtual, information and action and present and future. In this system, the network itself is the computer. A simple diagram of an ASES is shown in Fig. 6. The management in this system is conceptually different and decentralized; it is the management of a common pool of prosumption via creating an emergent anticipatory capacity and triggering action via effectors. The nature of this management is based on wrangler networking, closer social distance, collaborative and collective decisionmaking, and finally, high wrangler involvement in ASES management. 


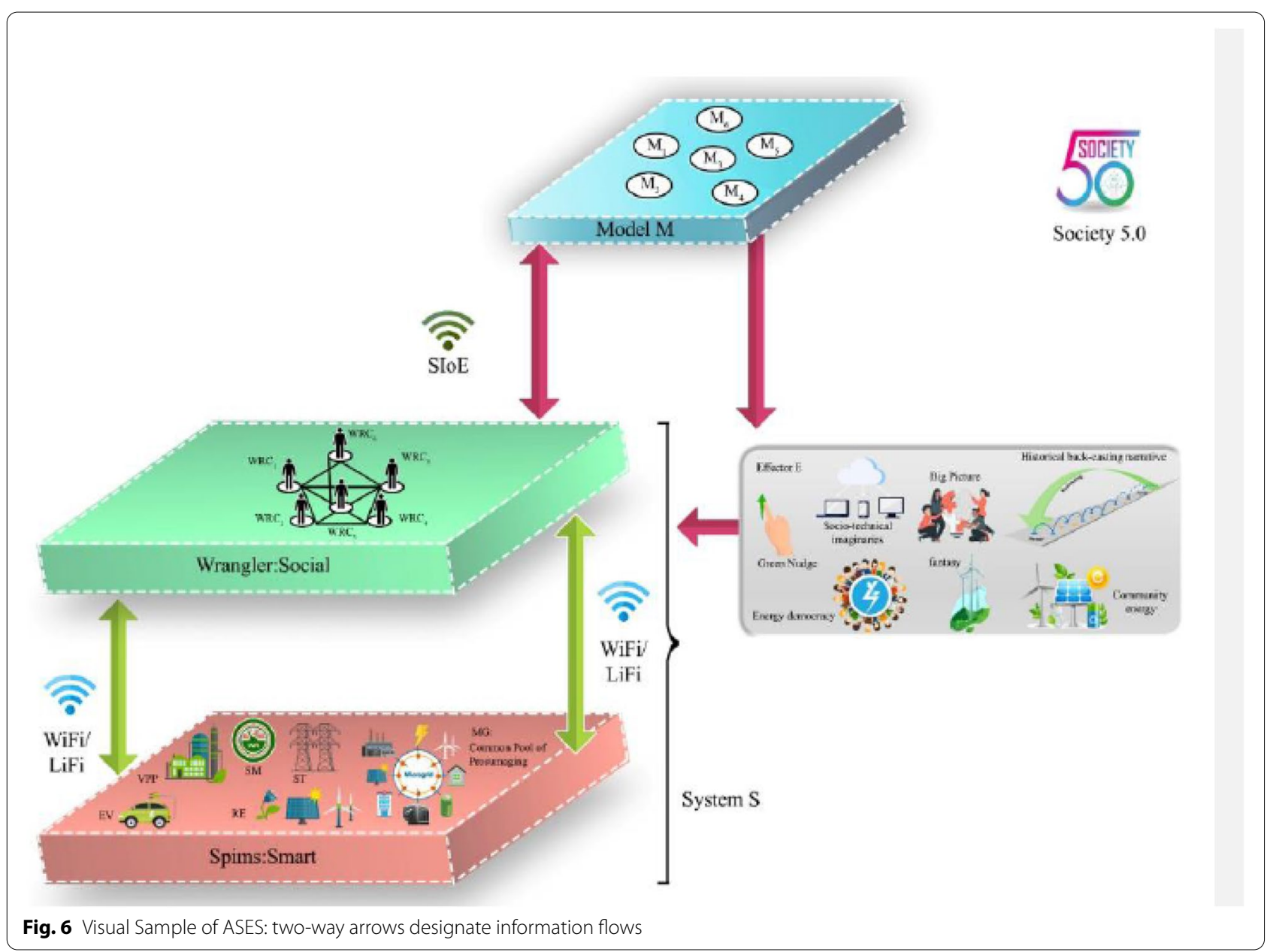

Also, as this system follows a maximal dataification approach to create the predictive model of the system protection of privacy sensitive information, security attacks on assets, data, network and application, and big data security threats in IoT are of great importance because they can damage the trust of the users threaten the reliability and stability of the ASES. Therefore, protocols similar to General Data Protection Regulation (GDPR) of European Union [176] are a pre-requisite in transition toward ASES.

Large scale ASES are not available yet but projects are being conducted to study features of such systems using anthropological approaches. SECURE project [177], for instance, intends to study the high levels of integration between cyber- physical, and social worlds. According to SECURE, presumption is the first and the most obvious form of this integration. The project is a "Techno-Anthropological investigation of how developers and future users relate to social and ethical issues of data sharing, privacy and trust". We do believe that the description and the conceptual model presented in this paper can be beneficial in thinking about the future of energy systems, its challenges and solutions as well as designing research project like SECURE to delve further into the specifications of ASES.

\section{Conclusion}

In this paper, we presented a reconfiguration of SESs and their problems and solutions using an anticipatory system lens through juxtaposition of Rosenian concepts of anticipatory system and SESs. Anticipatory system framework of energy is ambitiously intended to offer a common ground for a transdisciplinary, post-normal discussion with, bottom-up approach that should disentangle the complexity of energy systems.

According to Rosen's claim, the theory of the anticipatory system can be the foundation of the anticipatory paradigm as the future system paradigm including emerging energy systems; When the knowledge is the action, the future is experienced in the present, and in other words, the future is integrated into the extended present. Networked communities are connected and 
the crowdsourcing process acts like a computer. The maximum degree of integration of machine and human happens and society 5.0 is formed.

The crowdsourcing and participation of wranglers and ESTs create the maximum anticipatory capacity for the system. Because of the networked communities, the anticipatory capacity will be distributed, and the anticipatory behavior will become the constant feature in wrangler's behavior if and when three prerequisite conditions of the anticipatory system are materialized. In this paradigm, CPRs are common pool of prosumaging, and there will be no concern about the tragedy of common, because of crowdsourcing of the management of common resources. In this configuration, the ESTs and technical issues matter, but wranglers' behavior is of great importance and will be the basis of the energy system resilience. This is a paradigm shift from a smart and information-based society 4.0 to a super smart and human-centered society 5.0, in which the maximum degree of integration of machines and humans occurs.

\begin{abstract}
Abbreviations
ASES: Anticipatory smart energy system; SESs: Smart energy systems; VPP: Virtual power plant; MG: Micro grid; SG: Smart grid; SM: Smart meters; El/ loE: Energy internet/ internet of energy; EBD: Energy big data; ST: Smart transmission; RE: Renewable energy; EV: Electric vehicle; EST: Energy spime tools; DG: Distributed generation; DER: Distributed energy resource; SloE: Social internet of energy; SloT: Social internet of things; PCG: Prosumer community group; ICES: Integrated community energy system; CEC: Clean energy community; CPSS: Cyber-physical-social system; WRC: Wrangler community; CPR: Common pool resource.
\end{abstract}

\section{Acknowledgements}

Not applicable.

\section{Authors' contributions}

All authors contribute in this study. The author(s) read and approved the final manuscript.

\section{Funding}

Not applicable.

\section{Availability of data and materials}

Not applicable.

\section{Declarations}

Ethics approval and consent to participate

Not applicable.

\section{Consent for publication}

Not applicable.

\section{Competing interests}

The authors declare that they have no competing interests.

\section{Author details}

${ }^{1}$ Department of Industrial Engineering and Futures Studies, Faculty of Engineering, University of Isfahan, Isfahan, Iran. ${ }^{2}$ Department of Management, Faculty of Administrative Sciences and Economics, University of Isfahan, Isfahan, Iran.
Received: 4 April 2021 Accepted: 22 June 2021

Published online: 08 November 2021

\section{References}

1. R. Poli, The many aspects of anticipation, 12 (2010) 7-17. doi:https://doi. org/10.1108/14636681011049839

2. H. Duong-ngoc, T. Nguyen-minh, Short term load forcast using deep learning, 2019 Innov. Power Adv. Comput. Technol. (i-PACT). IEEE. 1 (2019) 1-5

3. Kriegler E, Bauer N, Popp A, Humpenöder F, Leimbach M, Stre J, Baumstark L, Leon B, Hilaire J, Klein D, Mouratiadou I, Weindl I, Bertram C, Dietrich J, Luderer G, Pehl M, Pietzcker R, Piontek F, Lotze-campen H, Biewald A, Bonsch M, Giannousakis A, Kreidenweis U, Müller C, Rolinski S, Schultes A, Schwanitz J, Stevanovic M, Calvin K, Emmerling J, Fujimori S, Edenhofer O (2016) Fossil-fueled development ( SSP5): An energy and resource intensive scenario for the 21 st century. Glob. Environ. Chang 42:297-315. https://doi.org/10.1016/j.gloenvcha.2016.05.015

4. A.A. Radionov, A.S. Karandaev, I.M. Yachikov, O.I. Karandaeva, Power Transformer Condition Forecast with Time-series Extrapolation, Proc. 9th Int. Conf. Comput. Autom. Eng. (2017) 326-330

5. T. Fuller, Technological forecasting \& social change anxious relationships : the unmarked futures for post-normal scenarios in anticipatory systems, Technol. Forecast. Soc. Chang. (2016). doi:https://doi.org/10. 1016/j.techfore.2016.07.045

6. M. Nadin, Anticipation across disciplines, Springer, 2016

7. Bale CSE, Varga L, Foxon TJ (2015) Energy and complexity : new ways forward. Appl Energy 138:150-159. https://doi.org/10.1016/j.apenergy. 2014.10.057

8. Michiel H, Heijnen P, Bouwmans I (2006) Socio-technical complexity in energy infrastructures, 2006 IEEE Int. Conf Syst Man Cybern 2:906-911

9. Ghomshei M, Villecco F, Pappalardo M (2009) Complexity in energy Policy : a fuzzy logic methodology, 2009 sixth Int. Conf Fuzzy Syst Knowl Discov IEEE 7:128-131. https://doi.org/10.1109/FSKD.2009.803

10. Bompard E, Connors S, Fulli G, Han B, Masera M, Mengolini A, Nuttall WJ (2012) Smart energy grids and complexity science. JRC Sci. Policy Rep. https://doi.org/10.2790/69368

11. O. Neagu, M.C. Teodoru, The Relationship between Economic Complexity, Energy Consumption Structure and Greenhouse Gas Emission : Heterogeneous Panel Evidence from the EU Countries, Sustainability. 11 (2019) 497. doi:https://doi.org/10.3390/su11020497

12. Marquardt J, Delina LL (2019) Energy Research \& Social Science Reimagining energy futures : contributions from community sustainable energy transitions in Thailand and the Philippines. Energy Res Soc Sci 49:91-102. https://doi.org/10.1016/j.erss.2018.10.028

13. S. Heinonen, J. Karjalainen, J. Ruotsalainen, K. Steinmüller, Surprise as the new normal - implications for energy security _ Enhanced Reader. pdf, Eur J Futur. Res. 5 (2017) 1-13. doi:https://doi.org/https://doi.org/ 10.1007/s40309-017-0117-5

14. Rosen J, Kineman JJ (2005) Anticipatory Systems and Time : a new look at Rosennean complexity. Off J Int Fed Syst Res 22:399-412

15. P. Bishop, Introduction to strategic foresight, (2018)

16. Sovacool BK, Ryan SE, Stern PC, Janda K, Rochlin G, Spreng D, Pasqualetti MJ, Wilhite H, Lutzenhiser L (2015) Energy Research \& Social Science Integrating social science in energy research. Energy Res Soc Sci 6:95-99. https://doi.org/10.1016/j.erss.2014.12.005

17. Popper Karl R (1963) Conjectures and refutations: the growth of scientific knowledge, 1963a. Routledge, London, UK

18. Stephenson J (2017) Energy Research \& Social Science What does energy mean? An interdisciplinary conversation. Chem Phys Lett 26:103-106. https://doi.org/10.1016/j.erss.2017.01.014

19. T.H. Morris, A.K. Srivastava, B. Reaves, K. Pavurapu, S. Abdelwahed, R. Vaughn, W. McGrew, Y. Dandass, Engineering future cyber-physical energy systems: challenges, research needs, and roadmap, in: 41 st north am. Power Symp., IEEE, 2009: pp. 1-6

20. L. Delina, A. Janetos, Energy Research \& Social Science Cosmopolitan, dynamic, and contested energy futures : Navigating the pluralities and polarities in the energy systems of tomorrow, Energy Res Soc Sci (2017) 0-1. doi:https://doi.org/10.1016/j.erss.2017.11.031 
21. K. Zhou, S. Yang, 5.11 Smart Energy Management, 2018. doi:https://doi. org/10.1016/B978-0-12-809597-3.00525-3

22. Watson RT, Boudreau M-C, Chen AJ (2010) Information systems and environmentally sustainable development: energy informatics and new directions for the IS community. MIS Q:23-38

23. Heghedus C, Chakravorty A, Rong C (2018) Energy informatics applicability; machine learning and deep learning, 2018 IEEE. Int. Conf. Big Data, Cloud Comput. Data Sci. Eng:97-101. https://doi.org/10.1109/ BCD2018.2018.00023

24. Greyson D (2019) The social informatics of ignorance. J Assoc Inf Sci Technol 70:412-415. https://doi.org/10.1002/asi.24143

25. Meyer ET, E-mail I, Willis M, Giles S, Ox UK, E-mail UK, Sawyer S (2019) The social informatics of knowledge. J Assoc Info Sci Tech 70:307-312. https://doi.org/10.1002/asi.24205

26. B. Bertenthal, R. Grossman, D. Hanley, M. Hereld, S. Kenny, G. Levow, M.E. Papka, S. Porges, K. Rajavenkateshwaran, R. Stevens, others, Social Informatics Data Grid, Proc. 3rd Int. Conf. ESocial Sci. (2007)

27. Sawyer S, Eschen KR (2001) Social informatics : perspectives, examples, and trends. Annu Rev Inf Sci Technol 36:427-465

28. Fonseca F, Marcinkowski M, Davis C (2018) Cyber-human Systems of Thought and Understanding. J Assoc Inf Sci Technol 70:402-411. https://doi.org/10.1002/asi.24132

29. Sovacool BK, Axsen J, Sorrell S (2018) Promoting novelty, rigor, and style in energy social science: towards codes of practice for appropriate methods and research design. Energy Res Soc Sci 45:12-42

30. Mallaband B, Wood G, Buchanan K, Staddon S, Mogles NM, Gabethomas E (2017) Energy research \& social science the reality of crossdisciplinary energy research in the United Kingdom : a social science perspective. Chem Phys Lett 25:9-18. https://doi.org/10.1016/j.erss. 2016.11.001

31. Spreng D (2014) Transdisciplinary energy research - reflecting the context. Energy Res. Soc. Sci. https://doi.org/10.1016/j.erss.2014.02.005

32. Ravetz J (2004) The post-normal science of precaution. Futures. 36:347-357

33. Boyd E, Nykvist B, Borgström S, Stacewicz IA (2015) Anticipatory governance for social-ecological resilience. Ambio. 44:149-161. https://doi. org/10.1007/s13280-014-0604-x

34. Rhodes DH, Ross AM (2009) Anticipatory capacity: leveraging modelbased approaches to design systems for dynamic futures. Int Conf Model Syst Eng MBSE 2009. https://doi.org/10.1109/MBSE.2009.5031719

35. Rosen R (1991) Life itself: a comprehensive inquiry into the nature, origin, and fabrication of life. Columbia University Press, New York

36. Marlen A, Maxim A, Ukaegbu IA, Nunna HSVSK (2019) Application of big data in smart grids : energy analytics, 2019 21st. Int. Conf. Adv. Commun. Technol:402-407. https://doi.org/10.23919/ICACT.2019.8701973

37. Z. Wei, S. Member, X.U. Zhu, S. Member, Energy-efficiency of millimeterwave full-duplex relaying Systems : challenges and solutions, 4 (2016)

38. Schnuelle C, Thoeming J, Wassermann T, Thier P, Von Gleich A, Goessling-reisemann S (2019) Energy Research \& Social Science Sociotechnical-economic assessment of power-to-X: potentials and limitations for an integration into the German energy system. Energy Res Soc Sci 51:187-197. https://doi.org/10.1016/j.erss.2019.01.017

39. Sarmah SB, Kalita P, Garg A, Niu X, Zhang X, Peng X, Bhattacharjee $D$ (2019) A review of state of health estimation of energy storage systems : challenges and possible solutions for futuristic applications of li-ion battery packs in electric vehicles. J. Electrochem. Energy Convers. Storage 16. https://doi.org/10.1115/1.4042987

40. Franjo IBDD, Pedersen GKAS (2017) The future of transportation in sustainable energy systems: Opportunities and barriers in a clean energy transition. Renew. Sustain. Energy Rev 82:1823-1838. https://doi.org/10. 1016/j.rser.2017.06.117

41. Gür TM (2018) Review of electrical energy storage technologies, materials and systems: challenges and prospects for large-scale grid storage. Energy Environ Sci 11:2696-2767

42. N. Mathews, N. Rao, B. Pattnaik, G.S. Prasad, Grid tied roof top solar: problems, learnings and solutions, in: 2016 first Int. Conf. Sustain. Green Build. Communities, IEEE, 2016: pp. 1-5

43. Saeed S, Badri A, Parvania M (2014) A survey on mobile energy storage systems ( MESS ): Applications, challenges and solutions. Renew Sust Energ Rev 40:161-170. https://doi.org/10.1016/j.rser.2014.07.183
44. Wang D, Liu L, Jia H, Wang W, Zhi Y, Meng Z, Zhou B (2018) Review of key problems related to integrated energy distribution systems. CSEE J. Power Energy Syst 4:130-145. https://doi.org/10.17775/CSEEJPES. 2018.00570

45. Ponds KT, Arefi A, Sayigh A, Ledwich G (2018) Aggregator of demand response for renewable integration and customer Engagement: strengths. Energies. 11:2391. https://doi.org/10.3390/en11092391

46. Shahinzadeh H, Hasanalizadeh-Khosroshahi A (2014) Implementation of smart metering systems: challenges and solutions. Telkomnika Indones J Electr Eng 12:5104-5109

47. Ahmad I, Kumar T, Liyanage M, Okwuibe J, Ylianttila M, Gurtov A (2018) Overview of $5 \mathrm{G}$ security challenges and solutions. IEEE Commun Stand Mag 2:36-43

48. Eissa MM (2018) Challenges and novel solution for wide-area protection due to renewable sources integration into smart grid : an extensive review. IET Renew Power Gener 12:1843-1853. https://doi. org/10.1049/iet-rpg.2018.5175

49. Q. Yang, Internet of things application in smart grid: a brief overview of challenges, opportunities, and future trends, in: smart power Distrib. Syst., Elsevier, 2019: pp. 267-283

50. Sigurjonsson HÆ, Clausen LR (2018) Solution for the future smart energy system : a polygeneration plant based on reversible solid oxide cells and biomass gasi fi cation producing either electrofuel or power. Appl Energy 216:323-337. https://doi.org/10.1016/j.apenergy. 2018.02.124

51. Islam SN, Baig Z, Zeadally S (2019) Physical layer security for the smart grid : vulnerabilities, threats and countermeasures. IEEE Trans Ind Informatics PP 1. https://doi.org/10.1109/TII.2019.2931436

52. V. Potdar, A. Chandan, S. Batool, N. Patel, Big Energy Data Management for Smart Grids-Issues, Challenges and Recent Developments, in: Smart Cities, Springer, 2018: pp. 177-205

53. Sani AS, Yuan D, Jin J, Gao L, Yu S, Dong ZY (2018) Cyber security framework for internet of things-based energy internet. Futur. Gener. Comput. Syst. https://doi.org/10.1016/j.future.2018.01.029

54. Buchanan K, Banks N, Preston I, Russo R (2016) The British public's perception of the UK smart metering initiative : threats and opportunities. Energy Policy 91:87-97. https://doi.org/10.1016/j.enpol.2016. 01.003

55. Wolsink M (2012) The research agenda on social acceptance of distributed generation in smart grids : renewable as common pool resources. Renew Sust Energ Rev 16:822-835. https://doi.org/10. 1016/j.rser.2011.09.006

56. M. Christine, G. Van de Kaa, N. Doorn, R. Künneke, Moral Values as Factors for Social Acceptance of Smart Grid Technologies, Sustainability. 10 (2018). doi:https://doi.org/10.3390/su10082703

57. Chin W, Li W, Chen H (2017) Energy big data security threats in loTbased smart grid communications. IEEE Commun Mag 55(10), 70-75

58. Huang C, Jhang J (2017) A renewables-based load-balancing energy management system for energy internet, 2017 IEEE 9th Int. Conf Commun Softw Networks:217-222

59. Tsagarakis KP (2020) Shallow geothermal energy under the microscope: social, economic, and institutional aspects. Renew Energy 147:2801-2808. https://doi.org/10.1016/j.renene.2019.01.004

60. Siddiqui F, Zeadally S, Alcaraz C, Galvao S (2012) Smart grid privacy: Issues and solutions. In 2012 21st International Conference on Computer Communications and Networks (ICCCN). IEEE, Munich, Germany; pp. 1-5

61. Smith J, Butler R, Day RJ, Goodbody AH, Llewellyn DH, Rohse M, Smith BT, Tyszczuk RA, Udall J, Whyte NM (2017) Gathering around stories : interdisciplinary experiments in support of energy system transitions. Energy Res Soc Sci 31:284-294

62. Biresselioglu ME, Nilsen M, Demir MH, Røyrvik J, Koksvik G (2018) Examining the barriers and motivators affecting European decisionmakers in the development of smart and green energy technologies. J Clean Prod 198:417-429

63. Sundararajan A, Chavan A, Saleem D, Sarwat Al (2018) A survey of protocol-level challenges and solutions for distributed energy resource cyber-physical security. Energies. 11:2360

64. Kalogridis G, Efthymiou C, Denic SZ, Lewis TA, Cepeda R (2010) Privacy for smart meters: Towards undetectable appliance load 
signatures. In 2010 First IEEE International Conference on Smart Grid Communications. IEEE; Gaithersburg, MD, USA; pp. 232-237

65. Rathnayaka AJD, Potdar VM, Dillon T, Hussain O, Kuruppu S (2014) Goal-oriented prosumer community groups for the smart grid. IEEE Technol Soc Mag 33:41-48

66. Leibowicz BD, Punjabi K, Shaughnessy EO, Margolis R (2019) Energy research \& social science rules of the rooftop : platform design and price reductions in an online solar photovoltaic marketplace in the United States. Energy Res Soc Sci 48:194-204. https://doi.org/10. 1016/j.erss.2018.10.010

67. Caballero V, Vernet D, Zaballos A (2019) Social internet of energy-a new paradigm for demand side management. IEEE Internet Things J 6:9853-9867

68. Seyfang G, Jin J, Smith A (2013) A thousand fl owers blooming ? An examination of community energy in the UK. Energy Policy 61:977-989. https://doi.org/10.1016/j.enpol.2013.06.030

69. Von Wirth T, Gislason L, Seidl R (2017) Distributed energy systems on a neighborhood scale : reviewing drivers of and barriers to social acceptance. Renew Sust Energ Rev:1-12. https://doi.org/10.1016/j. rser.2017.09.086

70. Peters D, Axsen J, Mallett A (2017) The role of environmental framing in socio-political acceptance of smart grid : The case of British Columbia , Canada. Renew Sust Energ Rev:1-13. https://doi.org/10. 1016/j.rser.2017.06.020

71. S. Batel, A critical discussion of research on the social acceptance of renewable energy generation and associated infrastructures and an agenda for the future future, J Environ Policy Plan 0 (2018) 1-14. doi:https://doi.org/10.1080/1523908X.2017.1417120

72. Mosannenzadeh F, Di Nucci MR, Vettorato D (2017) Identifying and prioritizing barriers to implementation of smart energy city projects in Europe: an empirical approach. Energy Policy 105:191-201. https:// doi.org/10.1016/j.enpol.2017.02.007

73. McCauley D, Ramasar V, Heffron RJ, Sovacool BK, Mebratu D, Mundaca $L$ (2019) Energy justice in the transition to low carbon energy systems: exploring key themes in interdisciplinary research. Appl Energy 233-234:916-921. https://doi.org/10.1016/j.apenergy.2018. 10.005

74. Corsini F, Certomà C, Dyer M, Frey M (2019) Participatory energy: research, imaginaries and practices on people'contribute to energy systems in the smart city. Technol Forecast Soc Change 142:322-332

75. Delina LL (2018) Energy Research \& Social Science Energy democracy in a continuum : remaking public engagement on energy transitions in Thailand. Energy Res Soc Sci 42:53-60. https://doi.org/10.1016/j. erss.2018.03.008

76. A. Marı, Barriers to social acceptance of renewable energy systems in Colombia ' $n$ and Viatcheslav Kafarov, Curr Opin Chem Eng 10 (2015) 103-110. doi:https://doi.org/https://doi.org/10.1016/j.coche.2015.08. 003

77. J. Kowalski, C. Biele, M. Mlodozeniec, M. Geers, Significance of social factors for effective implementation of smart energy management systems in end-user households, in: Int. Conf. Intell. Hum. Syst. Integr. Springer, 2018: pp. 119-124

78. Hoppe T (2019) Social innovation and the energy transition. Sustainability. 11:141. https://doi.org/10.3390/su11010141

79. Schubert C (2017) Green nudges: do they work? Are they ethical? Ecol Econ 132:329-342

80. Boomsma C, Hafner R, Pahl S, Jones RV, Fuertes A (2018) Should we play games where energy is concerned? perceptions of serious gaming as a technology to motivate energy behaviour change among social housing residents. Sustainability 10:1729

81. Bekebrede G (2018) Towards a joint local energy transition process in urban Districts : the GO2Zero simulation game. Sustainability. 10:1-20. https://doi.org/10.3390/su10082602

82. Nadin M (2012) The anticipatory profile. An attempt to describe anticipation as process. Int J Gen Syst 41:43-75. https://doi.org/10. 1080/03081079.2011.622093

83. M.-H. Caillol, Political anticipation and networks: creating anticipatory Systems for Government and Society, in: Anticip. Across Discip., Springer, 2016: pp. 379-391

84. R. Rosen, Anticipatory systems, in: Anticip. Syst., Springer, 2012: pp. $313-370$
85. Poli R (2010) An introduction to the ontology of anticipation. Futures. 42:769-776. https://doi.org/10.1016/j.futures.2010.04.028

86. Poli R (2009) The complexity of anticipation. Balk J Philos 1:19-29

87. Poli R (2015) The implicit future orientation of the capability approach. Futures.:1-9. https://doi.org/10.1016/j.futures.2015.03.002

88. Rosen R (1974) Planning, management, policies and strategies: four fuzzy concepts. Int J Gen Syst 1:245-252

89. A.H. Louie, R. Rosen, Robert Rosen 's anticipatory systems, 12 (2010) 18-29. doi:https://doi.org/10.1108/14636681011049848

90. MINCH E (1986) A review of:"ANTICIPATORY SYSTEMS", by Robert Rosen, Pergamon press, Oxford, 1985, X+ 436pp. Int J Gen Syst 12:405-409

91. R. Miller, R. Poli, Anticipatory systems and the philosophical foundations of futures studies, foresight. (2010)

92. P. Rossel, P. Rossel, Making anticipatory systems more robust, (2010). doi:https://doi.org/10.1108/14636681011049893

93. Cevolini A (2016) The strongness of weak signals: self-reference and paradox in anticipatory systems. Eur J Futur Res 4:1-13

94. Poli R (2014) Anticipation: what about turning the human and social sciences upside down? Futures. 64:15-18

95. Chiffi D, Pietarinen A-V, Proover M (2020) Anticipation, abduction and the economy of research: the normative stance. Futures. 115:102471

96. Kazakov R, Kunc M (2016) Foreseeing the dynamics of strategy: an anticipatory systems perspective. Syst Pract Action Res 29:1-25

97. D.M. Dubois, Mathematical foundations of discrete and functional systems with strong and weak anticipations, in: Anticip. Behav. Adapt. Learn. Syst., Springer, 2003: pp. 110-132

98. P. Taylor, R. Rosen, R. Rosen, International Journal Of General Systems Planning, Management, Policies And Strategies : Four Fuzzy Concepts † Planning, Management, Policies And Strategies : Four Fuzzy Conceptst, (2007) 37-41. doi:https://doi.org/10.1080/03081077408960784

99. Scolozzi R, Geneletti D (2017) Science of the Total environment the anthroposphere as an anticipatory system : open questions on steering the climate. Sci Total Environ 579:957-965. https://doi.org/10.1016/j. scitotenv.2016.10.086

100. Marien M (2009) Futures thinking and macro-Systems: illuminating our era of mal-adaptive, non-adaptive, and semi-adaptive Systems. World Futur Rev 1:5-13. https://doi.org/10.1177/194675670900100203

101. Wang F, Yuan Y, Wang X, Qin R (2018) Societies 5 . 0 : a new paradigm for computational social systems research. IEEE Trans. Comput. Soc. Syst 5:2-8. https://doi.org/10.1109/TCSS.2018.2797598

102. B. Sterling, Shaping things, (2005)

103. A. Toffler, T. Alvin, The third wave, Bantam books New York, 1980

104. Dennis K (2008) Sensoring the future: complex geographies of connectivity and communication. World Futures 64:22-33

105. Hodbod J, Adger WN (2014) Integrating social-ecological dynamics and resilience into energy systems research. Energy Res Soc Sci:1-6. https:// doi.org/10.1016/j.erss.2014.03.001

106. S. Africa,' Prosumers 'Are Evolving into' Prosumagers ';' Nonsumers'? It 's Not So Far-Fetched, 31 (2020) 75-76. doi:https://doi.org/10.1016/j.tej. 2018.07.009

107. D. Vernet, Social Internet of Energy - A new paradigm for Demand Side Management, 4662 (2019) 1-16. doi:https://doi.org/10.1109/JIOT.2019. 2932508

108. Wissner M (2011) The smart grid - a saucerful of secrets ? Appl Energy 88:2509-2518. https://doi.org/10.1016/j.apenergy.2011.01.042

109. J. Mankoff, J.A. Rode, Looking past yesterday's Tomorrow : using futures studies methods to extend the research horizon, (2013) 1629-1638

110. Prasad B, Koliou E, Friege J, Hakvoort RA, Herder PM (2016) Energetic communities for community energy : a review of key issues and trends shaping integrated community energy systems. Renew Sust Energ Rev 56:722-744. https://doi.org/10.1016/j.rser.2015.11.080

111. F. District, H. Systems, G.D. Heating, H. Lund, N. Duic, B.V. Mathiesen, N. Duic, B.V. Mathiesen, F. District, H. Systems, G.D. Heating, Future District Heating Systems and Technologies: on the role of smart energy Systems and 4 th Generation District, (2018). doi:https://doi.org/10.1016/j. energy.2018.09.115

112. Dincer I, Acar C (2017) Smart energy systems for a sustainable future. Appl Energy 194:225-235. https://doi.org/10.1016/j.apenergy.2016. 12.058

113. J.A. Robertson, D. Beer, J. Allen-robertson, D. Beer, Mobile Ideas: Tracking a Concept through Time and Space Mobile Ideas : Tracking a 
Concept through Time and Space, (2010) 37-41. doi:https://doi.org/10. 1080/17450101.2010.510336

114. M. Stead, P. Coulton, J. Lindley, Spimes Not Things . Creating A Design Manifesto For A Sustainable Internet of Things Spimes Not Things . Creating A Design Manifesto for A Sustainable Internet of Things, 6925 (2019). doi:https://doi.org/10.1080/14606925.2019. 1594936

115. K. Gorkovenko, D. Burnett, J. Thorp, D. Richards, D. Murray-Rust, Exploring the future of data-driven product design, Proc. 2020 CHI Conf. Hum. Factors Comput. Syst. (2019) 1-14

116. Powells G, Fell MJ (2019) Energy Research \& Social Science Flexibility capital and flexibility justice in smart energy systems. Energy Res Soc Sci 54:56-59. https://doi.org/10.1016/j.erss.2019.03.015

117. Alanne K, Saari A (2006) Distributed energy generation and sustainable development. Renew Sust Energ Rev 10:539-558. https://doi.org/10. 1016/j.rser.2004.11.004

118. E.A. Kosmatos, N.D. Tselikas, A.C. Boucouvalas, Integrating RFIDs and Smart Objects into a Unified Internet of Things Architecture, 2011 (2011) 5-12. doi:https://doi.org/10.4236/ait.2011.11002

119. Yu S, Fang F, Liu Y, Liu J (2019) Uncertainties of virtual power plant: problems and countermeasures. Appl Energy 239:454-470. https://doi. org/10.1016/j.apenergy.2019.01.224

120. M. Zajc, M. Kolenc, N. Suljanovi, Virtual power plant communication system architecture 11, (2019). doi:https://doi.org/10.1016/B978-0-12812154-2.00011-0

121. Van Summeren LFM, Wieczorek AJ, Bombaerts GJT, Verbong GPJ (2020) Energy research \& social science community energy meets smart grids : reviewing goals, structure, and roles in virtual power plants in Ireland , Belgium and the Netherlands. Energy Res Soc Sci 63:101415. https:// doi.org/10.1016/j.erss.2019.101415

122. Gayatri MTL, Parimi AM, Kumar AVP (2018) A review of reactive power compensation techniques in microgrids. Renew Sust Energ Rev 81:1030-1036. https://doi.org/10.1016/j.rser.2017.08.006

123. Hussain A, Bui V, Kim H (2019) Microgrids as a resilience resource and strategies used by microgrids for enhancing resilience. Appl Energy 240:56-72. https://doi.org/10.1016/j.apenergy.2019.02.055

124. E. Ostrom, Coping with tragedies of the commons, (1999) 493-535

125. Lorena M, Lochinvar M (2016) A review of the development of smart grid technologies. Renew Sust Energ Rev 59:710-725. https://doi.org/ 10.1016/j.rser.2016.01.011

126. Shaukat N, Khan B, Ali SM, Mehmood CA, Khan J, Farid U, Majid M, Anwar SM, Jawad M, Ullah Z (2017) A survey on electric vehicle transportation within smart grid system. Renew Sust Energ Rev:1-21. https://doi.org/10.1016/j.rser.2017.05.092

127. Vera YEG, Dufo-López R, Bernal-Agustín JL (2019) Energy management in microgrids with renewable energy sources: a literature review. Appl. Sci 9. https://doi.org/10.3390/app9183854

128. Dragičević T, Siano P, Prabaharan SR (2019) Future generation $5 G$ wireless networks for smart grid: a comprehensive review. Energies. 12:2140

129. Hu J, Vasilakos AV, Member S (2016) Energy big data analytics and security: challenges and opportunities. IEEE Trans. Smart Grid 7:2423-2436. https://doi.org/10.1109/TSG.2016.2563461

130. Zhou K, Fu C, Yang S (2020) Big data driven smart energy management: From big data to big insights. Renew Sust Energ Rev 56:215-225. https://doi.org/10.1016/j.rser.2015.11.050

131. Cao Y, Li Q, Tan Y, Li Y, Chen Y (2018) A comprehensive review of Energy Internet : basic concept, operation and planning methods, and research prospects. J Mod Power Syst Clean Energy 6:399-411. https:// doi.org/10.1007/s40565-017-0350-8

132. Hannan MA, Faisal M, Ker PJ, Mun LH, Parvin K, Mahlia TMI, Blaabjerg F (2020) A review of internet of energy based building energy management Systems : issues and recommendations. IEEE Access PP 1. https:// doi.org/10.1109/ACCESS.2018.2852811

133. Yan Z, Hu J (2018) Energy internet in the Yangtze River Delta: opportunities, challenges, and suggestions. Front Energy 12:484-492. https:// doi.org/10.1007/s11708-018-0600-0

134. T. Yang, Q. Guo, X. Tai, H. Sun, B. Zhang, W. Zhao, C. Lin, Applying blockchain technology to decentralized operation in future energy internet, in: 2017 IEEE Conf. Energy Internet Energy Syst. Integr., IEEE, 2017: pp. $1-5$
135. G. Ritzer, Correcting an historical error, in: keynote address Conf. Prosumption, Frankfurt, Ger. March, 2009

136. S. Halassi, J. Semeijn, N. Kiratli, S. Halassi, J. Semeijn, N. Kiratli, From consumer to prosumer : a supply chain revolution in 3D printing, (2018). doi:https://doi.org/10.1108/JPPLLM-03-2018-0139

137. G. Ritzer, P. Dean, N. Jurgenson, Behavioral Scientist The Coming of Age of the Prosumer, (2012). doi:https://doi.org/10.1177/0002764211429368

138. Hofman-kohlmeyer M (2019) Players as a prosumer . Individual motives for engaging in game modding. World Sci. News 133:191-203

139. Pal R, Chelmis C, Frincu M (2016) MATCH for the prosumer smart grid the Algorithmics of real-time power balance. IEEE Trans Parallel Distrib Syst 27:3532-3546. https://doi.org/10.1109/TPDS.2016.2544316

140. Kettunen P, Mäkitalo N (2019) Future smart energy software houses. Eur. J. Futur. Res. 7:1-25

141. Rathnayaka AJD, Potdar VM, Dillon T, Kuruppu S (2015) Electrical power and energy Systems framework to manage multiple goals in community-based energy sharing network in smart grid. Int J Electr Power Energy Syst 73:615-624. https://doi.org/10.1016/j.ijepes.2015. 05.008

142. W. Schill, Prosumage of solar electricity - the role of power-to-heat, (2017) 49-50

143. Sioshansi FP (2020) Innovation and disruption at the grid 's edge. Elsevier Inc. https://doi.org/10.1016/B978-0-12-811758-3/00001-2

144. E Espe, V Potdar, E Chang (2018) Prosumer communities and relationships in smart grids: a literature review, evolution and future directions. Energies 11(10):2528

145. Zhou Y, Wei Z, Sun G, Cheung KW, Zang H, Chen S (2018) A robust optimization approach for integrated community energy system in energy and ancillary service markets. Energy. 148:1-15. https://doi.org/ 10.1016/j.energy.2018.01.078

146. E. Minghui, I. Macgill, Energy research \& social science typology of future clean energy communities : An exploratory structure, opportunities, and challenges, Energy Res Soc Sci (2017) 0-1. doi:https://doi. org/10.1016/j.erss.2017.10.019

147. Shailendra S, Yassine A (2018) Big data Mining of Energy Time Series for behavioral analytics and energy consumption forecasting. Energies. 11:452. https://doi.org/10.3390/en11020452

148. B.M. Fukuyama, Society 5.0 : Aiming for a New Human-Centered Society, (2018) 47-50

149. M. Bajec, Smart City as a Platform-Based Ecosystem, in: Databases Inf. Syst. X Sel. Pap. from Thirteen. Int. Balt. Conf. DB\&IS 2018, IOS Press, 2019: p. 3

150. Onday O (2019) Japan's society 5.0: going beyond industry 4.0, bus. Econ J 10:1-6. https://doi.org/10.4172/2151-6219.1000389

151. Y.A. Prasetyo, A.A. Arman, Group management system design for supporting society 5.0 in smart society platform, in: 2017 Int. Conf. Inf. Technol. Syst. Innov., IEEE, 2017: pp. 398-404

152. Sheth A, Anantharam P, Henson C (2013) Physical-cyber-social computing: an early 21st century approach. EEE Intell Syst 28:78-82

153. Ashby WR (1961) An introduction to cybernetics. Chapman \& Hall Ltd, London. Fourth Impression

154. Smoker P (1969) Social research for social anticipation. Am Behav Sci 12:7-13

155. Zackery A, Shariatpanahi P, Zolfagharzadeh MM, Pourezzat AA (2016) Toward a simulated replica of futures: classification and possible trajectories of simulation in futures studies. Futures. 81:40-53. https://doi.org/ 10.1016/j.futures.2015.11.002

156. F. Reusswig, N. Komendantova, A. Battaglini, New governance challenges and conflicts of the energy transition: renewable electricity generation and transmission as contested socio-technical options, in: Geopolit. Renewables, Springer, 2018: pp. 231-256

157. Burke MJ, Stephens JC (2017) Energy Research \& Social Science Energy democracy: goals and policy instruments for sociotechnical transitions. Energy Res Soc Sci 33:35-48. https://doi.org/10.1016/j.erss.2017.09.024

158. Jantzen J, Kristensen M, Haunstrup T (2018) Sociotechnical transition to smart energy : the case of Samso 1997 e 2030. Energy. 162:20-34. https://doi.org/10.1016/j.energy.2018.07.174

159. Szulecki K (2017) Conceptualizing energy democracy Conceptualizing energy democracy. Env Polit 00:1-21. https://doi.org/10.1080/09644 016.2017 .1387294 
160. Mutter A (2019) Energy research \& social science mobilizing sociotechnical imaginaries of fossil-free futures - electricity and biogas in public transport in Linköping , Sweden. Energy Res Soc Sci 49:1-9. https://doi. org/10.1016/j.erss.2018.10.025

161. Strengers Y, Pink S, Nicholls L (2019) Energy research \& social science smart energy futures and social practice imaginaries : forecasting scenarios for pet care in Australian homes. Energy Res Soc Sci 48:108-115. https://doi.org/10.1016/j.erss.2018.09.015

162. I. Soutar, C. Mitchell, Energy research \& social science towards pragmatic narratives of societal engagement in the UK energy system, Energy Res Soc Sci (2017) 0-1. doi:https://doi.org/10.1016/j.erss.2017. 10.041

163. Simmet HR (2018) Energy research \& social science "lighting a dark continent ": imaginaries of energy transition in Senegal. Energy Res Soc Sci 40:71-81. https://doi.org/10.1016/j.erss.2017.11.022

164. L. Tozer, N. Klenk, Energy research \& social science discourses of carbon neutrality and imaginaries of urban futures, Energy Res Soc Sci (2017) 0-1. doi:https://doi.org/10.1016/j.erss.2017.10.017

165. J. Cloke, A. Mohr, E. Brown, Energy research \& social science imagining renewable energy : towards a social energy systems approach to community renewable energy projects in the global south, Energy Res Soc Sci (2017) 0-1. doi:https://doi.org/10.1016/j.erss.2017.06.023

166. Ballo IF (2015) Energy research \& social science imagining energy futures : sociotechnical imaginaries of the future smart grid in Norway. Chem Phys Lett 9:9-20. https://doi.org/10.1016/j.erss.2015.08.015

167. Delina LL (2017) Energy research \& social science whose and what futures? Navigating the contested coproduction of Thailand 's energy sociotechnical imaginaries. Energy Res Soc Sci:1-9. https://doi.org/10. 1016/j.erss.2017.10.045

168. A.A.M. Levenda, J. Richter, E. Fisher, Regional sociotechnical imaginaries and the governance of energy innovations, futures. (2018). doi:https:// doi.org/10.1016/j.futures.2018.03.001

169. Jasanoff S, Kim S (2013) Science as culture sociotechnical imaginaries and National Energy Policies Sociotechnical Imaginaries and National
Energy Policies. Sci Cult (Lond) 22:189-196. https://doi.org/10.1080/ 09505431.2013 .786990

170. Jasanoff S, Kim S-H (2015) Dreamscapes of modernity: sociotechnical imaginaries and the fabrication of power. University of Chicago Press, The United States

171. S. Jasanoff, Future imperfect: science, technology, and the imaginations of modernity, Dreamscapes Mod Sociotechnical Imaginaries Fabr Power (2015) 1-33

172. Eichler GM, Schwarz EJ (2019) What sustainable development goals do social innovations Address? A systematic review and content analysis of social innovation literature. Sustainability. 11:522. https://doi.org/10. 3390/su11020522

173. Hewitt RJ, Bradley N, Compagnucci AB, Barlagne C, Ceglarz A, Cremades R, Mckeen M, Otto IM, Slee B, Hewitt RJ (2019) Social innovation in community energy in Europe : a review of the evidence. Soc Innov Community Energy Eur A Rev Evid 7:1-27. https://doi.org/10.3389/ fenrg.2019.00031

174. Wiseman J (2017) Energy Research \& Social Science the great energy transition of the 21 st century : the 2050 zero-carbon world oration th. Energy Res Soc Sci:1-6. https://doi.org/10.1016/j.erss.2017.10.011

175. Poli R (2012) Steps toward an explicit ontology of the future. J Futur Stud 16:67-78

176. G.D.P. Regulation, General data protection regulation (GDPR), Intersoft Consult. Accessed Oct. 24.1 (2018)

177. Secure Estimation and Control Using Recursion and Encrytion (SECURE), (2017-2024), SECURE (aau.dk)

\section{Publisher's Note}

Springer Nature remains neutral with regard to jurisdictional claims in published maps and institutional affiliations.

\section{Submit your manuscript to a SpringerOpen ${ }^{\circ}$ journal and benefit from:}

- Convenient online submission

- Rigorous peer review

- Open access: articles freely available online

- High visibility within the field

- Retaining the copyright to your article

Submit your next manuscript at springeropen.com 